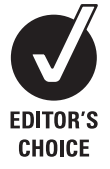

Department of Laboratory Medicine and Pathobiology, University of Toronto and University Health Network, Toronto, Ontario, Canada

Correspondence to: Associate Professor D Ghazarian, Department of Laboratory Medicine and Pathobiology, University of Toronto, University Health Network, 200 Elizabeth Street, Department of Pathology, 11th Floor, Toronto, Ontario, Canada M5G 2C4 danny.ghazarian@uhn.on.ca

Accepted 15 September 2008 Published Online First

17 October 2008

\title{
Non-melanocytic mimics of melanoma: Part I: intraepidermal mimics
}

\author{
Z S Kamil, L C B Tong, A Al Habeeb, D Ghazarian
}

\begin{abstract}
Melanoma comprises a wide range of cytological and architectural features histopathologically and hence can mimic many benign and malignant lesions of epithelial, mesenchymal and hematopoietic cell lines of differentiation. Therefore, analysis and close clinical, histological, histochemical and immunohistochemical correlation is vital in distinguishing challenging melanoma cases from their mimics. In this review, the different features of the benign, pre-malignant and malignant intraepidermal nonmelanocytic tumours and tumour-like lesions that can closely mimic intraepidermal melanoma (melanoma in situ) are emphasised.
\end{abstract}

Box 1 Most common intraepidermal mimics in pathology practice

- Clonal seborrhoeic keratosis or melanoacanthoma

- Bowen disease (squamous cell carcinoma in situ)

- Paget disease

Melanoma cells vary from epithelioid to spindle shape and may have diverse cytoplasmic morphologies such as histiocytic-like, clear cell, balloon cell, signet ring, rhabdoid and small cell. They arrange in different architectural patterns including nests, whorls, rosettes, trabeculae, nodules, glands and papillary formation. ${ }^{1}$ Thus, melanoma can be misdiagnosed and mistaken for many benign and malignant lesions. In addition, the absence or minimal presence of junctional component and small inadequate biopsy specimens can cause considerable confusion. ${ }^{2}$ Therefore, histochemical stains such as PAS, PASD, and colloidal iron and immunohistochemical stains ${ }^{3-6}$ are used extensively to differentiate melanoma from other tumour and tumour-like lesions, but this should be done in the context of close clinical and histological correlation (see fig 1). Ultrastructural examination may be used in rare circumstances to help to establish the diagnosis.

In this review, we classify the intraepidermal non-melanocytic mimics according to their biological behaviour as benign, pre-malignant, uncertain and malignant (fig 2).

\section{INTRAEPIDERMAL BENIGN MIMICS OF MELANOMA}

\section{Clear cell papulosis}

Clear cell papulosis (CCP) is a very rare disease, which has been mainly described in young children. Clinically, CCP is characterised by multiple small white papules on the lower part of the abdomen, lumbar region or buttock. Microscopically, there is mild acanthosis and scattered clear cells, which are larger than the neighbouring keratinocytes with no atypia, mainly distributed along the basal layer of the epidermis with only focal extension into the stratum spinosum. Mucicarmine, colloidal iron, Alcian blue and periodic acid-Schiff (PAS) demonstrate cytoplasmic mucin. ${ }^{2}$ Immunohistochemically, the clear cells stain for AE1/AE3 cytokeratin, monoclonal carcinoembryonic antigen (mCEA), epithelial membrane antigen (EMA) and gross cystic disease fluid protein-15 (GCDFP-15). ${ }^{27}$

They can be distinguished from melanoma in situ (fig 3) by the lack of melanin, nesting and cytological atypia. In addition, histochemical and immunohistochemical examination (table 1) demonstrate the epithelial nature of the clear cells. Electron microscopy demonstrates desmosomal junctions.

\section{Pagetoid dyskeratosis}

Pagetoid dyskeratosis (PD) is an incidental finding in a variety of skin and squamous mucosal lesions from diverse sites including the cervix, lips and prepuce. It is considered to be a selective keratinocyte response to friction. Histologically, there are scattered bland cells with a pyknotic nuclei, perinuclear halo and pale cytoplasm in the upper layers of the epidermis. The PD cells stain positive for high molecular weight cytokeratin $(\mathrm{HMWCK})^{89}$ and stain negative for m-CEA, $\mathrm{HMB}-45^{\circ}$ and $\mathrm{S} 100$ protein. In addition, $\mathrm{PD}$ cells are negative for mucin stains.

They can be distinguished from melanoma in situ based on the absence of atypia, nesting and negative staining for melanoma markers (table 1).

\section{Toker cell hyperplasia}

Toker cell hyperplasia (TCH) is an incidental finding and does not result in any clinical abnormality. Toker cells (TCs) are intraepithelial cells, which are mainly found around the openings of the lactiferous ducts in the epidermis. The cells are bland, and have round nuclei and clear pale cytoplasm. Nucleoli can be prominent or inconspicuous. TCs predominate in the basal layer of the epidermis and can contain intracytoplasmic pigment.

Absence of pleomorphism and cytological atypia help to separate this condition from melanoma in situ with the aid of immunohistochemistry (table 1). ${ }^{9}$ 


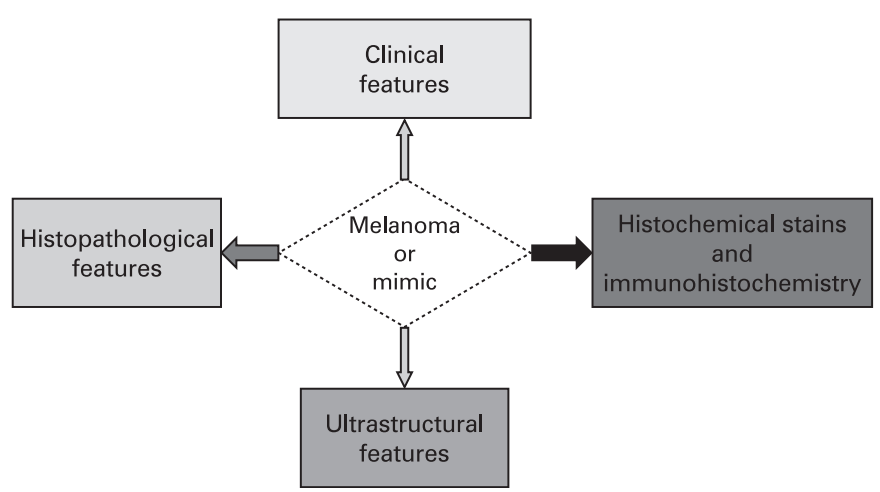

Figure 1 Features used to help differentiate melanoma from its mimics.

\section{Granular cell tumour with epidermal involvement}

Granular cell tumour (GCT) is a tumour of nerve sheath origin, so called because of the coarse cytoplasmic granularity that is typically found among its constituent cells.

Histologically, the cells are plump, spindle and epithelioid with abundant eosinophilic cytoplasm and inconspicuous bland nuclei. These cells are mainly found in the superficial dermis with varying degree of epidermal extension. ${ }^{10}$ The growth pattern can be that of short fascicles, nested or lentiginous arrangement. Accordingly these tumours can be easily confused with melanocytic lesions. Immunohistochemistry plays an important role in differentiating GCT from melanoma (table 1). ${ }^{10} 11$ Ultrastructural studies have shown the cytoplasmic granules of GCT to be secondary lysosomes.

\section{Seborrhoeic keratosis}

Seborrhoeic keratoses (SK) are benign hyperplastic tumours of the epidermis that mostly affect elderly Caucasian patients. Clinically, SK are slightly raised, tan to brown or black papules with sun-exposed skin being mostly affected. The pigmented variant of SK can closely mimic melanoma clinically. ${ }^{12}$ Izikson et al studied the prevalence of melanoma clinically resembling seborrhoeic keratosis in 9204 cases; lesions submitted for histological examination included those in which clinical diagnosis of seborrhoeic keratosis was offered or those with a differential diagnosis that included seborrhoeic keratosis. Clinicopathological analysis of melanomas revealed that any histological type of melanoma could mimic SK. The study also suggested that melanomas clinically resembling seborrhoeic keratosis might share some histological features of SK, such as hyperkeratosis, acanthosis, horn pseudocysts, verrucoid or papillomatous architecture, and epidermal hyperpigmentation. ${ }^{13}$

Histologically, clonal or nested SK can mimic melanoma since it is characterised by well defined nests of cells within the epidermis that are composed of fairly large cells with distinct intercellular bridges. The nests are separated from each other by strands of cells showing small dark nuclei; in other instances, the nests are composed of basaloid cells with small dark staining nuclei and intercellular bridges seen in only a few areas. Melanoacanthoma (fig 4A), a rare variant of pigmented SK, can also mimic melanoma in situ by showing a marked increase in the concentration of melanocytes. These melanocytes are scattered throughout the tumour lobules rather than being confined to the basal cell layer; they are large and richly dendritic and contain variable amounts of melanin (box 1).

Figure 2 Non-melanocytic mimics of intraepidermal melanoma (melanoma in situ).

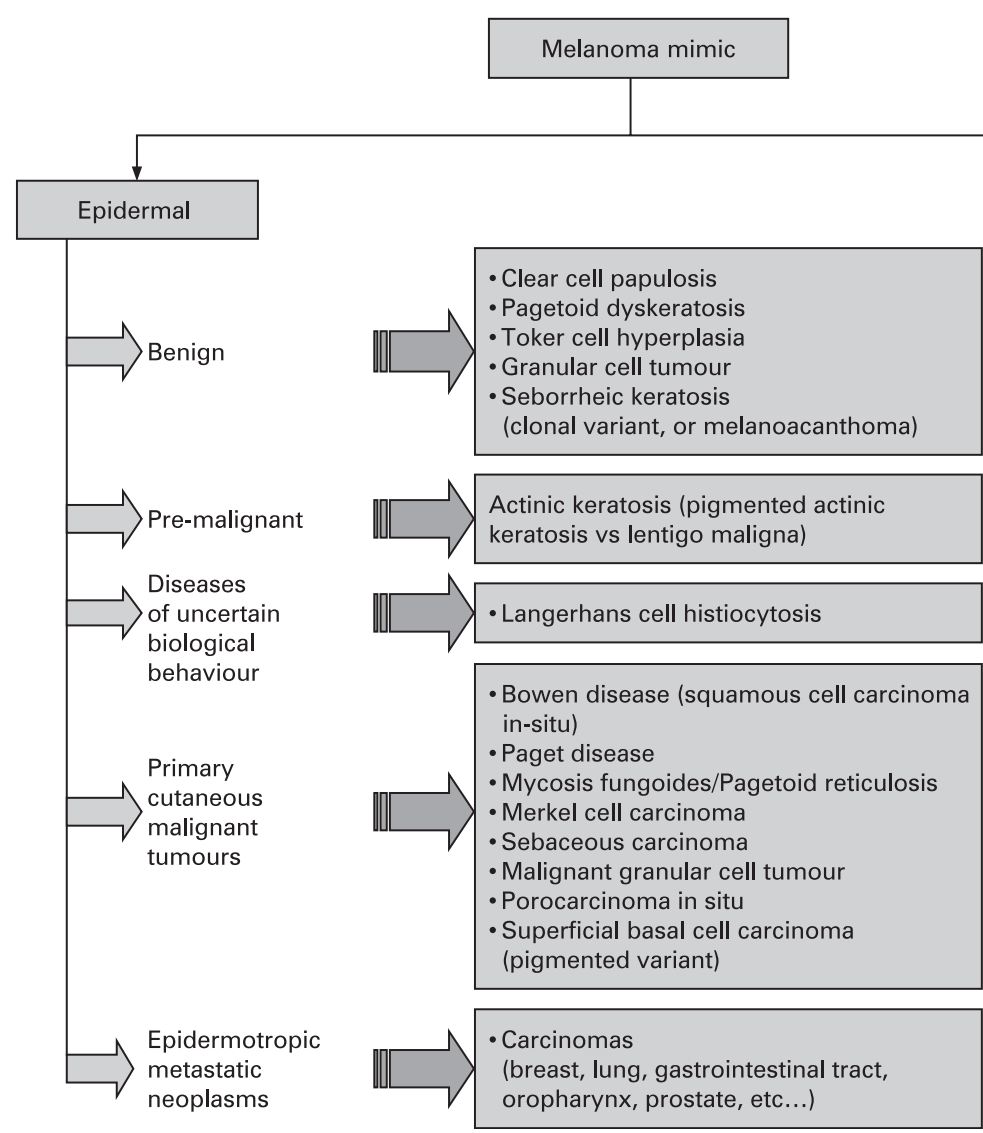


Table 1 Histopathological and immunohistochemical features of benign intraepidermal mimics of melanoma

\begin{tabular}{|c|c|c|}
\hline Intraepidermal mimic & Histopathological features & Immunohistochemical features \\
\hline Clear cell papulosis & $\begin{array}{l}\text { Scattered clear cells along the basal layer of the epidermis } \\
\text { Lack of melanin, nesting, cytological atypia }\end{array}$ & $\begin{array}{l}\text { AE1/AE3 cytokeratin }(+), \text { mCEA (+), EMA }(+) \text {, GCDFP-15 (+) } \\
\text { S100 (-), HMB } 45(-) \text {, Mart 1/Melan A (-) }\end{array}$ \\
\hline Pagetoid dyskeratosis & $\begin{array}{l}\text { Scattered bland cells with pyknotic nuclei, perinuclear halo and } \\
\text { pale cytoplasm in the upper layers of the epidermis } \\
\text { - Absence of atypia, nesting }\end{array}$ & $\begin{array}{l}\text { HMWCK (+) } \\
\text { mCEA (-), HMB } 45(-), \text { S-100 (-), Mart 1/Melan A (-) }\end{array}$ \\
\hline Toker cell hyperplasia & $\begin{array}{l}\text { Bland cells with round nuclei and clear pale cytoplasm that } \\
\text { predominate in the basal layer of the epidermis } \\
\text { Absence of pleomorphism and cytological atypia }\end{array}$ & $\begin{array}{l}\text { EMA }(+), \text { LMWCK }(+) \text {, CK } 7(+) \\
\text { HMWCK }(-) \text {, mCEA (-), HMB } 45(-) \text {, Mart 1/Melan A (-) }\end{array}$ \\
\hline $\begin{array}{l}\text { Clonal seborrhoeic keratosis } \\
\text { or melanoacanthoma }\end{array}$ & $\begin{array}{l}\text { Well defined nests of large cells with distinct intercellular bridges } \\
\text { or basaloid cells with small dark staining nuclei } \\
\text { Large, dendritic melanocytes scattered through the epidermis } \\
\text { in the melanoacanthoma variant } \\
\text { - Columns and sheets of basaloid to squamoid cells with intervening } \\
\text { horn cysts and slender elongated rete ridges } \\
\text { - Absence of cytological atypia }\end{array}$ & $\begin{array}{l}\text { HMWCK (+) (fig 4B), P63 (+) (fig 4C) } \\
\text { S-100 (-) (fig 4D), HMB 45 (-), Mart 1/Melan A (-) }\end{array}$ \\
\hline
\end{tabular}

CK, cytokeratin; EMA, epithelial membrane antigen; GCDFP-15, gross cystic disease fluid protein-15; HMWCK, high molecular weight cytokeratin; LMWCK, low molecular weight cytokeratin; mCEA, monoclonal carcinoembryonic antigen.

In addition to these features, intervening horn cysts, and slender elongated interlocking rete ridges are seen in SK.

Distinction from melanoma is mainly based on morphological features and immunohistochemistry (table 1).

\section{INTRAEPIDERMAL PRE-MALIGNANT MIMICS OF MELANOMA Actinic keratosis}

Actinic keratoses (AK) are very common on sun exposed skin in people with fair skin, particularly of the face, scalp, ears and forearms. On histological examination, AK demonstrates partial thickness dysplasia of keratinocytes with parakeratosis and hypogranulosis. The pigmented variant of AK shows pigmentation of keratinocytes in the lower layers of the epidermis (table 2). In cases of associated solar lentigo, there is elongation of rete ridges and an increase in the number of basal melanocytes but with no cytological atypia. However, this can be mistaken for melanoma in situ of solar type (lentigo maligna).

Distinction of AK from melanoma in situ of the solar type can be very challenging, especially in the presence of increased basal keratinocyte pigmentation. Although the morphology can be of help, immunohistochemistry is often required to achieve the right diagnosis, especially in small biopsy specimens (table 1). ${ }^{2}$ Examining multiple levels might be necessary in such cases.

\section{CUTANEOUS DISEASES OF UNCERTAIN BIOLOGICAL BEHAVIOUR MIMICKING MELANOMA}

\section{Langerhans cell histiocytosis}

Skin involvement is frequent in both acute and chronic Langerhans cell histiocytosis (LCH); however, it has been reported only rarely in patients as the sole manifestation of the disease. It usually affects children, but can present in all ages. Clinically, it presents as scaly, crusted papules or plaques; the scalp, face and genital areas are the most commonly involved locations.

Confusion with melanoma only occurs when there is prominent infiltration of the epidermis by Langerhans cells (LCs), especially when examining small biopsy specimens. Microscopic features of Langerhans cells together with immunohistochemistry help to separate this condition from melanoma. On histology, there are
Figure 3 In situ melanoma. (A) Atypical melanocytes mainly distributed at the dermo-epidermal junction with upward migration (arrowheads) (H\&E stain; original magnification $\times 400$ ).

(B) Melanoma cells (arrows) showing immunoreactivity to HMB-45 immunostain (original magnification $\times 400)$.
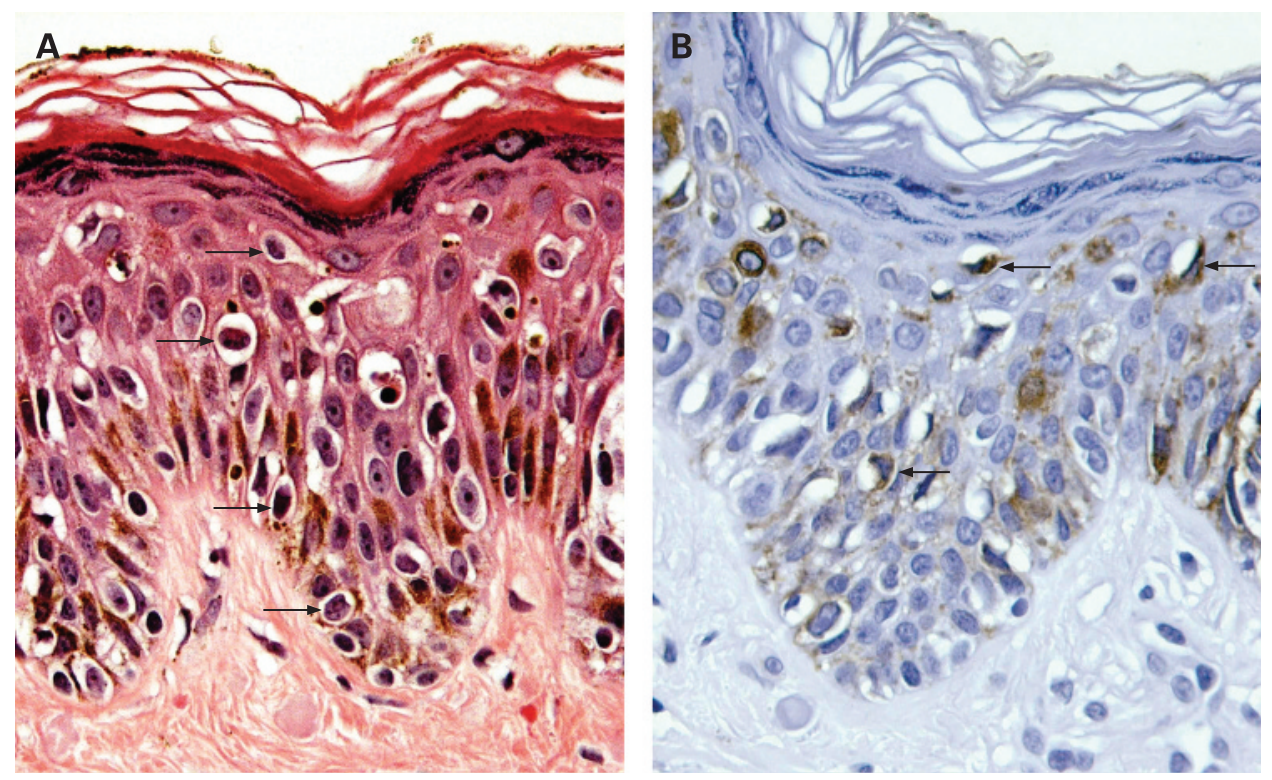
Figure 4 Pigmented clonal seborrhoeic keratosis. (A) Infiltration of the epidermis with nests of atypical cells (arrowheads). Pigmented cells and horn cysts are also seen (H\&E stain; original magnification $\times 200$ ). (B) High molecular weight cytokeratin immunostain showing strong positivity of the nested cells (original magnification $\times 200$ ). (C) P63 is highlighting the clear nuclear staining of keratinocytes within the nests (original magnification $\times 200$ ). (D) S100 protein stain is negative within the nests. The brown pigment (arrows) is melanin (original magnification $\times 200$ ).
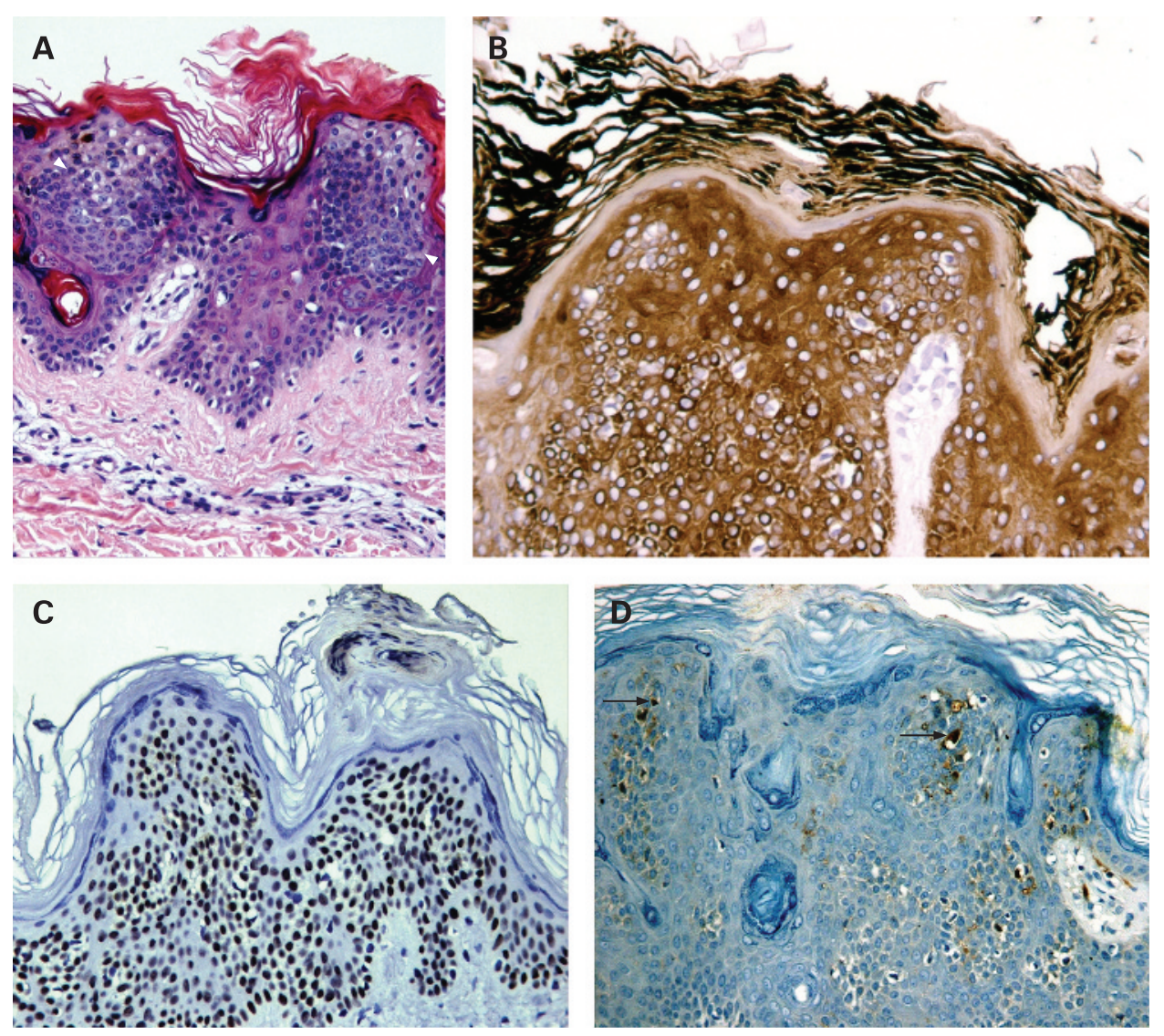

aggregates of Langerhans cells seen in the epidermis, which are characterised by abundant blue-grey cytoplasm, indented oval nuclei with a central groove and little or no cytological atypia. Dermal pattern also helps to rule out melanoma, as Langerhans cells form sheets with accentuation below the epidermis (table 3). Eosinophils are often present. In addition, the absence of melanin pigment is another helpful feature in LCH. Immunohistochemically, Langerhans cells are positive for S100 and CD1a, but negative for other melanocytic markers. ${ }^{2}{ }^{14} 15$ Ultrastructurally, rod or rocket shaped granules (Birbeck granules, Langerhans cell granules) is the diagnostic hallmark of LCs.

\section{INTRAEPIDERMAL PRIMARY CUTANEOUS MALIGNANT MIMICS OF MELANOMA}

\section{Bowen disease (squamous cell carcinoma in situ)}

Bowen disease (BD) is a squamous cell carcinoma in situ, which presents as solitary, scaly, red plaque. There is predilection for sun-exposed skin. On histology, there is full-thickness keratinocyte dysplasia with acanthosis, hyperkeratosis, parakeratosis, dyskeratotic cells and frequent mitotic figures above the basal cell layer, few of which are atypical (fig 5). Pigmented and nonpigmented variants of $\mathrm{BD}$ may mimic melanoma clinically, but can be readily separated from melanoma by cytomorphological features (table 4). ${ }^{16}$ Pagetoid (clonal) BD (fig 5) can be easily confused with melanoma in situ and often is challenging to the examining pathologist. It shows a Pagetoid pattern with widely scattered atypical pale keratinocytes in all layers of the epidermis separated from each other by normal keratinocytes. However, Pagetoid BD does not tend to be pigmented; tumour cells are positive for HMWCK and P63 (nuclear positivity) (table 4) and negative for melanocytic markers. ${ }^{2}{ }^{17}$ A Pagetoid pattern may be seen in Bowenoid papulosis (squamous cell carcinoma in situ of the external genitalia); the same features used for $\mathrm{BD}$ can be applied to differentiate this entity from melanoma in situ. Occasionally, sharply demarcated nests of atypical cells are identified within the epidermis, an example of the BorstJadassohn phenomenon, also known as nested Bowen disease. ${ }^{18}$ This variant of $\mathrm{BD}$ can be further confused with melanoma in situ. However, the same criteria mentioned above can be used to differentiate these lesions from melanoma (box 1).

\section{Mammary and extramammary Paget disease}

Mammary Paget disease is a rare disease affecting the nipple and areola. It mostly affects females in their fifth or sixth decade and

Table 2 Histopathological and immunohistochemical features of pre-malignant intraepidermal mimics of melanoma

\begin{tabular}{|c|c|c|}
\hline Intraepidermal mimic & Histopathological features & Immunohistochemical features \\
\hline Actinic keratosis & $\begin{array}{l}\text { Partial thickness dysplasia of keratinocytes } \\
\text { Pigmentation of keratinocytes in the lower layers of the epidermis in the } \\
\text { pigmented variant } \\
\text { No extension of melanocytes into neighbouring hair follicles } \\
\text { Absence of nesting or crowding of melanocytes at the dermo-epidermal } \\
\text { junction }\end{array}$ & $\begin{array}{l}\text { S-100 and Mart 1/Melan A are helpful to highlight the epidermal } \\
\text { melanocytes and distinguish them from the atypical keratinocytes } \\
\text { HMWCK or P63 can be used to highlight the keratinocytes }\end{array}$ \\
\hline
\end{tabular}


Table 3 Histopathological and immunohistochemical features of cutaneous diseases of uncertain biological behaviour that can mimic melanoma

\begin{tabular}{lll}
\hline Intraepidermal mimic & Histopathological features & Immunohistochemical features \\
\hline Langerhans cell histiocytosis* & Aggregates of Langerhans cells in the epidermis characterised by abundant blue-grey cytoplasm, & S-100 (+), CD1a (+) \\
& indented oval nuclei with a central groove \\
& Little or no cytological atypia \\
& Dermal infiltrate of Langerhans cells that form sheets with accentuation below the epidermis \\
& Absence of melanin pigment, and presence of eosinophils
\end{tabular}

*The ultrastructural hallmark of Langerhans cells is the rod or rocket shaped granules (Birbeck granules, Langerhans cell granules), which may be needed to establish the diagnosis of Langerhans cell histiocytosis.

is almost always associated with an underlying mammary duct carcinoma.

Extramammary Paget disease is also a rare disease that usually presents in the sixth to eight decades of life with most cases occurring in the vulva, scrotum, and perianal and perineal regions.

Both diseases have similar histological features. The epidermis shows infiltration of large cells with abundant pale or eosinophilic cytoplasm and large vesicular nuclei. The cells are scattered throughout all layers of the epidermis and arranged in clusters or singly (fig 6A). Mitotic figures can be seen. The epidermis shows acanthosis, parakeratosis and hyperkeratosis. Pigmented tumour cells may be seen or pigmentation can be due to epidermal colonisation by non-neoplastic melanocytes.

Differentiating these conditions from melanoma in situ can be difficult, especially in pigmented lesions. Therefore, the diagnosis depends on a precise histological examination, correlated with immunohistochemical analysis. ${ }^{19}$ Histologically, the nesting pattern in Paget disease is usually seen above the basal cell layer of the epidermis and not mainly at the dermo-epidermal junction as seen in melanoma. ${ }^{20}$ Histochemistry and immunohistochemistry further help to distinguish Paget disease from melanoma in situ. A PAS diastase stain shows the presence of neutral mucopolysaccharides in Paget disease. The tumour cells stain positive with colloidal iron (Hale stain) (fig 6B), LMWCK (fig 6C), EMA, CEA and GCDFP15 , and negative for melanocytic markers (box 1, table 4). ${ }^{2} 919$

\section{Mycosis fungoides/Pagetoid reticulosis}

Pagetoid reticulosis (PR), also known as Woringer-Kolopp disease, is a rare variant of mycosis fungoides (MF) according to the current World Health Organization that presents with localised patches and plaques mainly involving the distal extremities and characterised by prominent intraepidermal

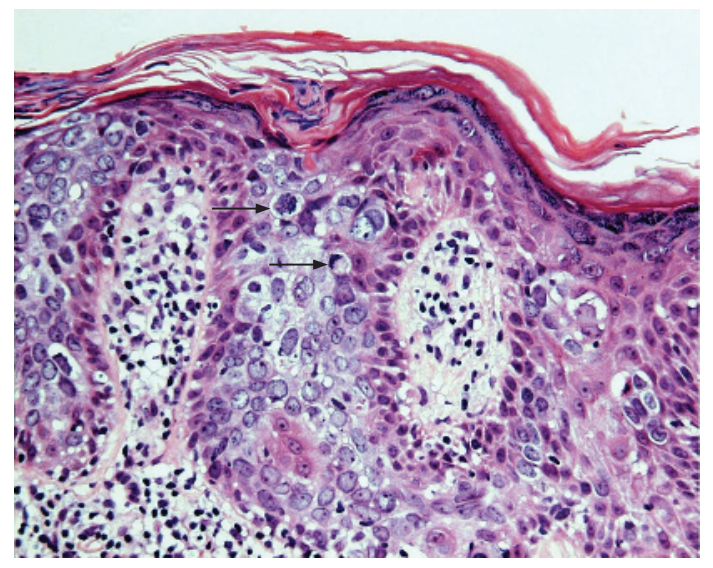

Figure 5 Bowen disease. Pagetoid infiltration of the epidermis with large atypical keratinocytes. Mitotic figures are shown (arrows) (H\&E stain; original magnification $\times 200$ ).
Pagetoid spread of the tumour cells. ${ }^{21}$ The clinical, histological and immunophenotypic findings of PR overlap with those of early patch stage MF.

Both PR and MF can be mistaken for amelanotic melanoma clinically and histologically. On histology, PR demonstrates acanthosis, hyperkeratosis with focal parakeratosis and prominent infiltration of the epidermis by large, irregular, often cerebriform lymphoid cells with a moderate amount of lightly eosinophilic cytoplasm and large nuclei with irregular nuclear contour. The cells arrange in single units or nests, which are mainly seen in the lower layers of the epidermis. The dermis demonstrates an infiltrate composed predominantly of mature and reactive lymphocytes, histiocytes, and sometimes few plasma cells. ${ }^{22-24} \mathrm{MF}$ has similar histological features to PR (fig 7A,B). The tumour cells are positive for CD3 (fig 7C), either CD4 positive, less likely CD8 positive, or CD4/CD8 double negative; they variably stain for other T-cell markers such as CD5 and are usually negative for CD7..$^{25-27}$ The melanocytic markers are negative. Rare cases of CD56 positive MF have been reported in the literature (table 4). ${ }^{25-27}$

Clinicopathological correlation helps to distinguish these lesions from melanoma with clinical features being of supreme importance in guiding diagnosis, prognosis and therapy.

\section{Merkel cell carcinoma}

Merkel cell carcinoma (MCC) is a primary neuroendocrine carcinoma of the skin that mainly involves the head and neck and extremities (mainly dorsum of the hands) of older adults and presents clinically as a solitary rapidly growing hard nodule. Microscopically, MCC is a small, round, blue cell tumour that is often characterised by nested or trabecular pattern of growth, high mitotic rate and frequent single-cell necrosis, and sometimes zonal necrosis. One of its histological differential diagnoses includes small cell melanoma. However, histological correlation with the clinical data and immunohistochemistry can help rule out melanoma. Histologically, MCC consists of small monomorphic basophilic tumour cells with round to oval shaped nuclei and scanty cytoplasm. The nuclei have finely granular dispersed chromatin and small inconspicuous nucleoli. The tumour cells mainly occupy the dermis and may extend into the subcutaneous fat, however; Pagetoid spread of the tumour cells into the epidermis, although rare, can occur and has been reported. ${ }^{28}$ A dense lymphocytic infiltrate is characteristically present within the tumour and surrounding area.

Immunohistochemically, MCC is usually positive for LMWCK and CK20 (typical dot-like paranuclear or cytoplasmic staining), negative for CK7, variably positive for CD56, CD57, EMA, chromogranin and synaptophysin, and negative for melanocytic markers (table 4). ${ }^{29}{ }^{30}$ Electron microscopy demonstrates the neuroendocrine nature of MCC cells by showing dense core neurosecretory granules, paranuclear aggregates of 
Table 4 Histopathological and immunohistochemical features of intraepidermal primary cutaneous malignant tumours mimicking melanoma

\begin{tabular}{|c|c|c|}
\hline Intraepidermal mimic & Histopathological features & Immunohistochemical features \\
\hline Bowen disease & $\begin{array}{l}\text { Full-thickness keratinocyte dysplasia with acanthosis, parakeratosis and frequent } \\
\text { mitotic figures above the basal cell layer } \\
\text { Widely scattered atypical pale keratinocytes in all layers of the epidermis in Pagetoid } \\
\text { BD separated from each other by normal keratinocytes } \\
\text { Sharply demarcated nests of atypical cells within the epidermis in the nested variant } \\
\text { of BD }\end{array}$ & $\begin{array}{l}\text { HMWCK }(+) \text { P63 (+) (nuclear stain) } \\
\text { Negative for melanocytic markers (S-100, Mart 1/ } \\
\text { Melan A, HMB 45) }\end{array}$ \\
\hline $\begin{array}{l}\text { Mammary and } \\
\text { extramammary Paget disease }\end{array}$ & $\begin{array}{l}\text { Large cells with abundant pale or eosinophilic cytoplasm containing large vesicular } \\
\text { nuclei. The cells are scattered throughout all layers of the epidermis, but the nesting } \\
\text { pattern is usually seen above the basal cell layer } \\
\text { Melanin pigment can be seen in some cases } \\
\text { Mucin stains such as colloidal iron can be of great help. PAS diastase is also positive }\end{array}$ & $\begin{array}{l}\text { LMWCK (+), CEA (+), EMA (+), GCDFP-15 (+), CK7 (+) } \\
\text { Negative for melanocytic markers (S-100, Mart 1/ } \\
\text { Melan A, HMB 45) }\end{array}$ \\
\hline $\begin{array}{l}\text { Mycosis fungoides/Pagetoid } \\
\text { reticulosis }\end{array}$ & $\begin{array}{l}\text { Infiltration of the epidermis by large irregular lymphoid cells with a moderate amount } \\
\text { of lightly eosinophilic cytoplasm and large cerebriform nuclei } \\
\text { Cells arrange in single units or nests and are mainly seen in the lower layers of the } \\
\text { epidermis (epidermotropism) } \\
\text { In mycosis fungoides Pautrier microabscesses can be seen } \\
\text { Dermal infiltrate of mature and reactive lymphocytes, histiocytes and few plasma } \\
\text { cells }\end{array}$ & $\begin{array}{l}\text { CD3 }(+), \operatorname{CD} 5( \pm) \text {, mainly CD4 }(+) \text {, less likely CD8 }(+) \text {, } \\
\text { or CD4/CD8 double-negative } \\
\text { Rare variant of mycosis fungoides shows CD56 } \\
\text { positivity } \\
\text { Usually negative for CD7 and melanocytic markers* } \\
\text { (S-100, HMB 45, Mart 1/Melan A) }\end{array}$ \\
\hline Merkel cell carcinoma & $\begin{array}{l}\text { Small monomorphic basophilic cells with round to oval shaped nuclei and scanty } \\
\text { cytoplasm } \\
\text { Nuclei have finely granular dispersed chromatin and small inconspicuous nucleoli } \\
\text { Tumour cells mainly occupy the dermis, but Pagetoid spread of the tumour cells into } \\
\text { the epidermis can be seen }\end{array}$ & $\begin{array}{l}\text { CK20 (+) and LMWCK }(+) \text { typical dot-like paranuclear } \\
\text { or cytoplasmic staining, variably positive for CD56, } \\
\text { CD57, EMA, chromogranin and synaptophysin } \\
\text { S-100 }(-) \text {, HMB } 45(-) \text {, Mart 1/Melan A (-) }\end{array}$ \\
\hline $\begin{array}{l}\text { Sebaceous carcinoma with } \\
\text { Pagetoid spread }\end{array}$ & $\begin{array}{l}\text { Tumour composed of basaloid appearing cells with varying degree of sebaceous } \\
\text { differentiation } \\
\text { Intraepidermal Pagetoid spread of tumour cells can be seen } \\
\text { Cells are vacuolated with scalloped, mulberry-like pattern nuclei. Mitotic figures are } \\
\text { frequent }\end{array}$ & $\begin{array}{l}\text { AE1/AE3 cytokeratin }(+), \text { LMWCK }(+), \text { EMA }(+), \\
\text { androgen receptor protein }(+), \text { CK14 }(+), \text { P63 } \\
\text { focally }(+) \\
\text { S-100 }(-) \text {, HMB } 45(-) \text {, Mart 1/Melan A (-) }\end{array}$ \\
\hline $\begin{array}{l}\text { Malignant granular cell } \\
\text { tumour }\end{array}$ & $\begin{array}{l}\text { Nuclear atypia (prominent nucleoli), nuclear pleomorphism } \\
->2 \text { mitoses/10 HPF } \\
\text { Increased nuclear/cytoplasmic ratio } \\
\text { Necrosis, spindling }\end{array}$ & $\begin{array}{l}\text { S100 }(+), \text { CD68 }(+) \text {, inhibin }(+) \text {, calretinin }(+) \\
\text { Negative for other melanocytic markers (HMB 45, } \\
\text { Mart 1/Melan A) }\end{array}$ \\
\hline Porocarcinoma in situ & $\begin{array}{l}\text { Nests of atypical polygonal cells that are sharply separated from the adjacent } \\
\text { epidermis } \\
\text { Cytonuclear atypia, hyperchromatic nuclei and prominent nucleoli } \\
\text { - Cells may contain melanin } \\
\text { Adjacent benign poroid component can be present within occasional tubules }\end{array}$ & $\begin{array}{l}\text { S-100 occasionally }(+) \text {, pancytokeratin }(+), \text { CK7 } \\
\text { focally }(+) \\
- \text { HMB } 45(-) \text {, Mart 1/Melan } A(-)\end{array}$ \\
\hline $\begin{array}{l}\text { Pigmented superficial basal } \\
\text { cell carcinoma }\end{array}$ & $\begin{array}{l}\text { Basaloid cells with atypical nuclei, scant cytoplasm and peripheral palisading of the } \\
\text { cells } \\
\text { Melanocytes scattered through the tumour nests and melanophages within the } \\
\text { stroma }\end{array}$ & $\begin{array}{l}\text { HMWCK }(+), \text { CK14(+), BerEP4 }(+) \text {, focally }(+) \text { for CK7 } \\
\text { and LMWCK } \\
\text { Negative for melanocytic markers (S-100, HMB 45, } \\
\text { Mart 1/Melan A) }\end{array}$ \\
\hline
\end{tabular}

*Other melanocytic markers such as cytoplasmic tyrosinase or nuclear microphthalmia transcription factor can be used in some cases if necessary.

†Very rare tumour.

intermediate sized filaments, complex intercellular junctions and cytoplasmic spinous processes.

\section{Sebaceous carcinoma with Pagetoid spread}

Sebaceous carcinoma is more common in the eyelids than extraocular sites and presents clinically as a rapidly growing non-tender mass in middle-aged and elderly patients. Histopathologically, the tumour is lobular and composed of basaloid appearing cells with varying degrees of sebaceous differentiation. The pattern is that of an asymmetric, nonencapsulated, infiltrating, expansile basaloid cell neoplasm located in the dermis with an infiltrative margin. ${ }^{31} 32$ Intraepidermal Pagetoid spread of the tumour cells can be confused with melanoma. On careful histological examination, the tumour cells are usually vacuolated with scalloped nuclei (table 4). Mitotic figures are frequent and pleomorphism is variable. By immunohistochemistry, the tumour cells stain positive for AE1/AE3 cytokeratin, LMWCK, EMA and androgen receptor protein (nuclear staining) and negative for S100 protein and other melanocytic markers. ${ }^{32}$ It is our observation that sebaceous tumours, including sebaceous carcinomas, are positive for CK14. Ultrastructurally, the principal feature is the presence of intracytoplasmic lipid droplets. In addition, desmosomes are seen between tumour cells.

\section{Malignant granular cell tumour}

Malignant granular cell tumours (malignant GCTs) are rare tumours that make up less than $2 \%$ of all granular cell tumours. ${ }^{33}$

These tumours tend to be larger than their benign counterparts and are rarely seen in children. Histologically, malignant GCTs are similar to benign ones, but have constellation of histological features that favour malignancy. These features include nuclear atypia with prominent nucleoli, nuclear pleomorphism, increased nuclear/cytoplasmic ratio, increased mitotic activity $(>2 / 10 \mathrm{HPF})$, spindling and necrosis. ${ }^{10}$ Tumours that have three or more of these criteria are considered malignant with an increased risk for metastasis.

Distinction from melanoma in most cases can be achieved by immunohistochemistry (table 4) when cytomorphological features do not lead to a definitive diagnosis.

\section{Porocarcinoma in situ}

Porocarcinomas (malignant eccrine poromas), ${ }^{34}$ are usually found on the lower extremities. They usually arise in pre-existing benign 

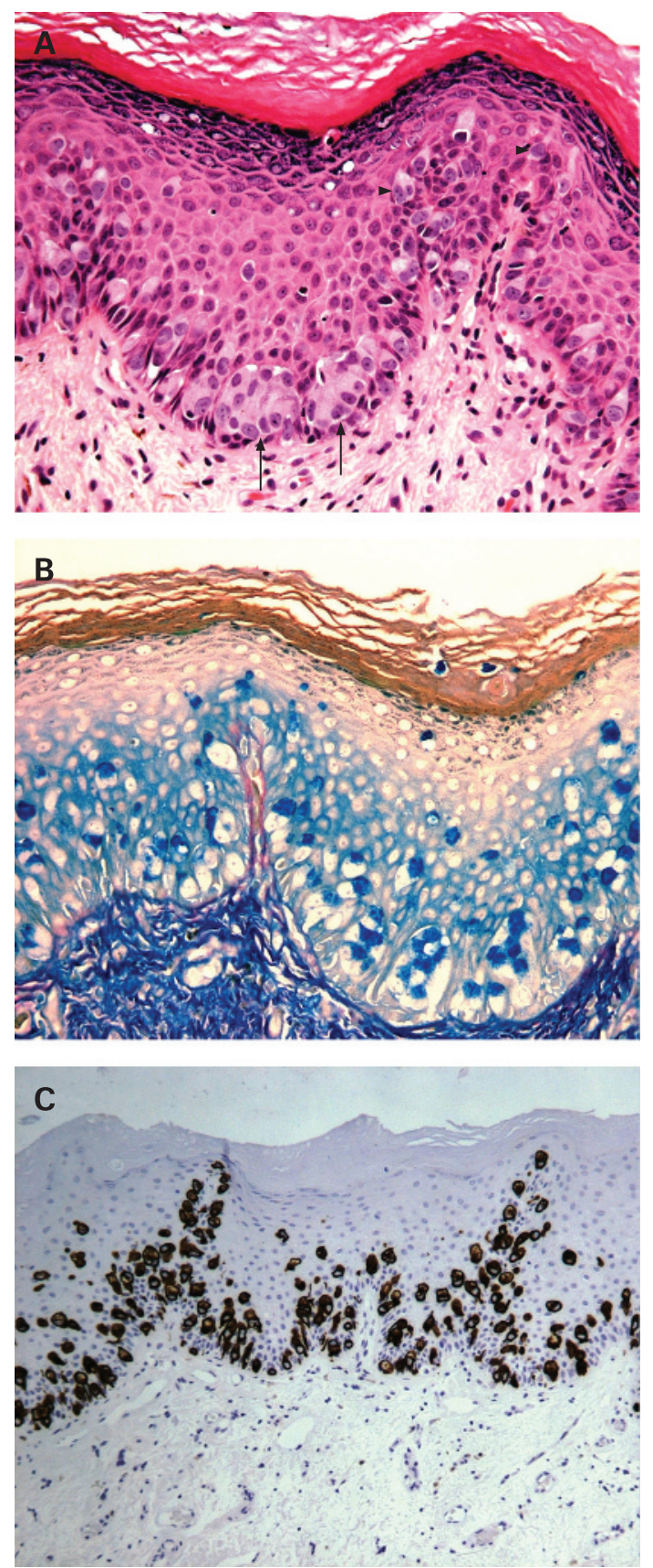

Figure 6 Paget disease of the nipple. (A) The epidermis is infiltrated with atypical large pale cells arranged in single units and nests (arrows) with upward migration (arrowheads) (H\&E stain; original magnification $\times 200$ ). (B) Colloidal iron shows positive mucin staining within the atypical cells (original magnification $\times 200$ ). (C) Low molecular weight cytokeratin highlights the Christmas tree immunoreactivity of the Pagetoid cells in Paget disease (original magnification $\times 100$ ).

poroid tumours. Histologically, porocarcinoma in situ can closely mimic melanoma in situ, as it is characterised by nests of atypical polygonal cells that are sharply separated from the adjacent epidermis. The neoplastic cells may have basaloid features and show varying degrees of cytonuclear atypia, hyperchromatic nuclei and prominent nucleoli and may contain melanin. Large polyhedral cells with abundant clear cytoplasm can be seen. Eccrine differentiation in the form of CEA positive tubular formation is usually present in some of the cases. The presence of an adjacent benign poroid component is a helpful feature in
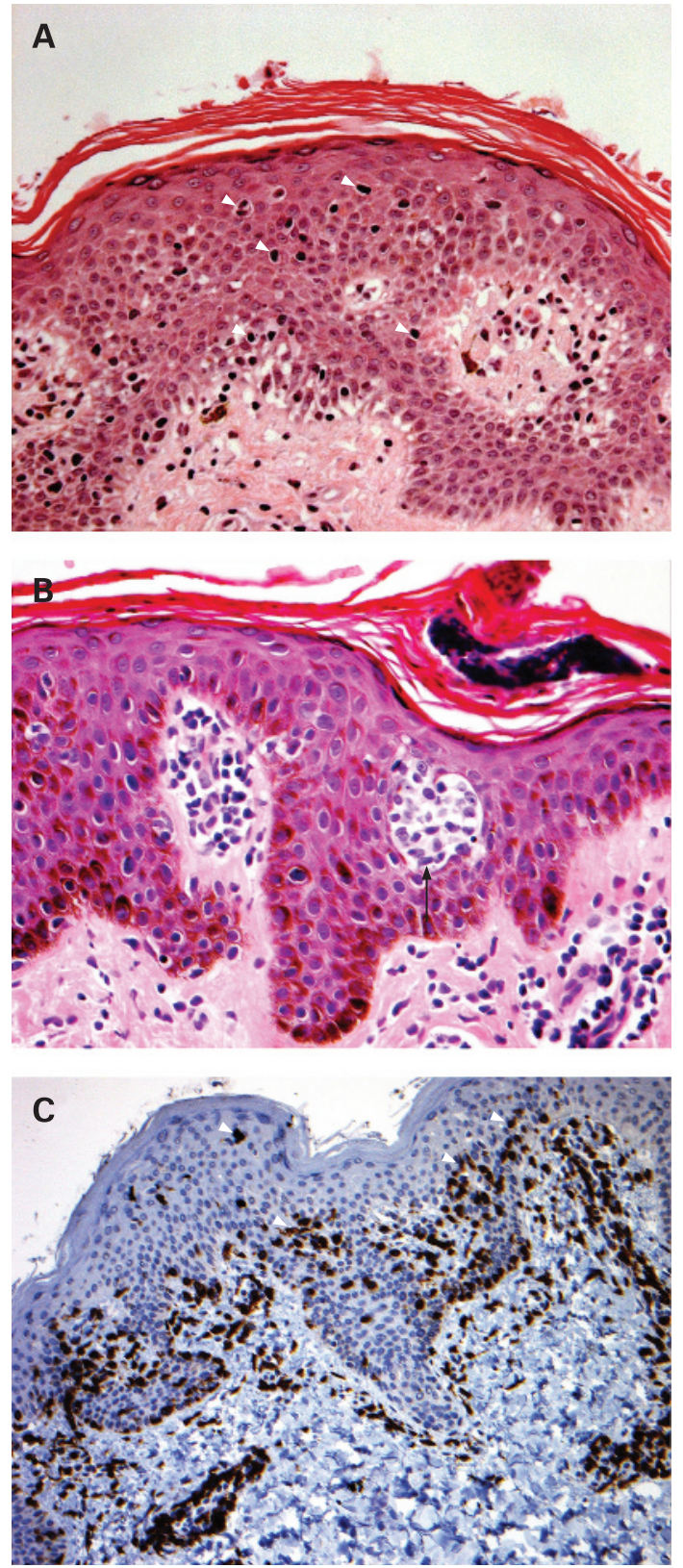

Figure 7 Mycosis fungoides (MF). (A) Low power view showing infiltration of the epidermis with large irregular lymphoid cells (arrowheads) in a Pagetoid pattern (H\&E stain; original magnification $\times 200$ ). (B) High power view showing collection of atypical lymphocytes within the epidermis:

"Pautrier microabscesses" (arrow) (H\&E stain; original magnification $\times 400$ ). (C) Positive staining of atypical lymphocytes (arrowheads) with CD3 (T-cell lymphocyte marker) (original magnification $\times 200$ ).

establishing the diagnosis. Immunohistochemically, the neoplastic cells are occasionally positive for S100 and strongly positive for pancytokeratin (table 4). Negativity for Mart 1/Melan A and HMB-45 helps rule out melanoma in situ. ${ }^{34}$ On electron microscopy, the neoplastic cells show intracytoplasmic lumens. ${ }^{35}$

\section{Pigmented superficial basal cell carcinoma}

Basal cell carcinoma (BCC) can be easily distinguished both clinically and histologically from melanoma. However, the pigmented variant of superficial BCC can mimic melanoma clinically; the problem is usually solved on histological examination. ${ }^{36}$ Histologically, superficial BCC consists of columns, cords, 


\section{Take-home messages}

- Melanoma can mimic many benign and malignant lesions of different lineages because of its cytomorphological and architectural diversity.

- Thorough analysis with close clinical, histological and immunohistochemical correlation is required to diagnose melanoma or one of its mimics.

- Immunohistochemical markers (melanocytic and nonmelanocytic) are essential in establishing the diagnosis of melanoma or its mimics.

lobules of basaloid cells with atypical nuclei, scant cytoplasm, and peripheral palisading of cells. Artefactual clefting can be seen underneath the tumour. In addition to these features, the pigmented variant of superficial BCC also contains melanocytes scattered through the tumour nests and melanophages within the stroma (table 4). Immunohistochemically, the neoplastic cells are positive for HMWCK, CK14 and BerEP4, focally positive for CK7 and LMWCK, and negative for melanocytic markers.

\section{EPIDERMOTROPIC METASTATIC MIMICS OF MELANOMA}

Epidermotropic metastatic carcinomas, even though rarely seen, pose a diagnostic dilemma. Cancers of the breast, lung, prostate, gastrointestinal tract and oropharynx can metastasise in an epidermotropic pattern and mimic melanoma. ${ }^{37}{ }^{38}$

The clinical information from the patient is the most important piece of evidence for determination of the nature of the process in these cases. Differentiating a melanoma from an epidermotropically metastatic carcinoma can be challenging. Morphologically, the tumour cells from epidermotropic metastatic carcinomas may be arranged in nests, small glands or singly at all levels of epidermis in a Pagetoid pattern. In addition to epidermal involvement, the neoplastic cells are generally found in the dermis. Immunohistochemistry is very helpful in distinguishing melanomas from metastatic carcinomas. Immunoreactivity with cytokeratins and immunonegativity for melanocytic markers help make the distinction from melanoma. A well known example of such mimic is pigmented epidermotropic metastatic breast carcinoma, which is the most common epidermotropic metastatic carcinoma. The tumour cells in breast carcinoma are arranged in strands, cords and ductlike structures with melanocytes and melanophages interspersed among the tumour cells. The features that help to differentiate it from melanoma include the relative absence of junctional nesting and positive staining of the atypical cells for cytokeratin, EMA, CEA and GCDFP-15. ${ }^{39}{ }^{40}$ On the other hand, melanocytic markers are usually negative in epidermotropic metastatic breast carcinoma. ${ }^{40}$

Competing interests: None.

\section{REFERENCES}

1. Banerjee SS, Harris M. Morphological and immunophenotypic variations in malignant melanoma. Histopathology 2000;36:387-402.

2. Calonje E. Non-melanocytic lesions mimicking melanocytic lesions. Pathology 2004;36:387-95

3. Clarkson KS, Sturdgess IC, Molyneux AJ. The usefulness of tyrosinase in the immunohistochemical assessment of melanocytic lesions: a comparison of the novel T311 antibody (antityrosinase) with S-100, HMB-45, and A103 (anti-Melan-A). J Clin Pathol 2001;54:196-200.

4. Ohsie SJ, Sarantopoulos GP, Cochran AJ, et al. Immunohistochemical characteristics of melanoma. J Cutan Pathol 2008;35:433-44.
5. Granter SR, Weilbaecher KN, Quigley C, et al. Microphthalmia transcription factor: not a sensitive or specific marker for the diagnosis of desmoplastic melanoma and spindle cell (non-desmoplastic) melanoma. Am J Dermatopathol 2001;23:185-9.

6. King $\mathbf{R}$, Weilbaecher KN, McGill G, et al. Microphthalmia transcription factor. A sensitive and specific melanocyte marker for melanoma diagnosis. AJP 1999;155:731-8.

7. Mohanty SK, Arora R, Kakkar N, et al. Clear cell papulosis of the skin. Ann Diagn Pathol 2002;6:385-8.

8. Garijo MF, Val D, Val-Bernal JF. Pagetoid dyskeratosis of the lips. Am J Dermatopathol 2001:23:329-33.

9. Garijo MF, Val D, Val-Bernal JF. Pagetoid dyskeratosis of the nipple epidermis: an incidental finding mimicking Paget's disease of the nipple. APMIS 2008;116:139-46.

10. Ray S, Jukic DM. Cutaneous granular cell tumor with epidermal involvement: a potential mimic of melanocytic neoplasia. J Cutan Pathol 2007;34:188-94.

11. Gleason BC, Nascimento AF. HMB-45 and Melan-A are useful markers in the differential diagnosis between granular cell tumor and malignant melanoma. Am J Dermatopathol 2007;29:22-7.

12. Giorgi V, Massi D, Salvini C, et al. Pigmented seborrheic keratoses of the vulva clinically mimicking a malignant melanoma: a clinical, dermoscopic-pathologic case study. Clin Exp Dermatol 2005;30:17-9.

13. Izikson L, Sober AJ, Mihm MC, et al. Prevalence of melanoma clinically resembling seborrheic keratosis. Arch Dermatol 2002;138:1562-6.

14. Punia RS, Bagai M, Mohan $\mathrm{H}$, et al. Langerhans cell histiocytosis of skin: a clinicopathologic analysis of five cases. Indian J Dermatol Venereol Leprol 2006; 72:211-4.

15. Meehan SA, Smoller BR. Cutaneous Langerhans cell histiocytosis of the genitalia in the elderly: a report of three cases. J Cutan Pathol 1998;25:370-4.

16. Krishnan R, Lewis A, Orengo IF, et al. Pigmented Bowen's disease (squamous cell carcinoma in situ): a mimic of malignant melanoma. Dermatol Surg 2001;27:673-4.

17. Rosen L, Amazon K, Frank B. Bowen's disease, Paget's disease, and malignant melanoma in situ. South Med J 1986;79:410-3.

18. Patterson JW, Wick MR. Epidermal tumors. In: Nonmelanocytic tumors of the skin Washington, DC: American Registry of Pathology, 2006:33.

19. Pizzichetta MA, Canzonieri V, Massarut S, et al. Pigmented mammary Paget's disease mimicking melanoma. Melanoma Res 2004;14:S13-5.

20. Mitchell S, Lachica R, Randall MB, et al. Paget's disease of the breast areola mimicking cutaneous melanoma. Breast J 2006;12:233-6.

21. Miedler JD, Kristjansson AK, Gould J, et al. Pagetoid reticulosis in a 5-year-old boy. J Am Acad Dermatol 2008;58:679-81.

22. Haghighi B, Smoller BR, LeBoit PE, et al. Pagetoid reticulosis (Woringer-Kolopp disease): an immunophenotypic, molecular, and clinicopathologic study. Mod Pathol 2000;13:502-10.

23. Dusan S, Zoran B, Sonja V, et al. Pagetoid reticulosis of Woringer-Kolopp. Dermatol Online J 2008;14:18.

24. Ioannides G, Engel M, Rywlin A. Woringer-Kolopp disease (Pagetoid reticulosis). Am J Dermatopathol 1983;5:153-8.

25. Hodak E, David M, Maron L, et al. CD4/CD8 double-negative epidermotropic cutaneous T-cell lymphoma: an immunohistochemical variant of mycosis fungoides. J Am Acad Dermatol 2006;55:276-84.

26. Wain EM, Orchard GE, Mayou S, et al. Mycosis fungoides with a CD56+ immunophenotype. J Am Acad Dermatol 2005;53:158-63.

27. Klekotka PA, Faulkner-Jones B, Heffernan MP. A case of CD56+mycosis fungoides Arch Dermatol 2006;142:1370-2.

28. LeBoit PE, Crutcher WA, Shapiro PE. Pagetoid intraepidermal spread in Merkel cell (primary neuroendocrine) carcinoma of the skin. Am J Surg Pathol 1992;16:584-92.

29. Bickle K, Frank Glass L, Messina JL, et al. Merkel cell carcinoma: a clinical, histopathologic, and immunohistochemical review. Semin Cutan Med Surg 2004;23:46-53.

30. Smith KJ, Skelton III HG, Holland TT, et al. Neuroendocrine (Merkel cell) carcinoma with an intraepidermal component. Am J Dermatopathol 1993;15:528-33.

31. Hassanein AM. Sebaceous carcinoma and the T-antigen. Semin Cutan Med Surg 2004;23:62-72.

32. Alsaad KO, Obaidat NA, Ghazarian D. Skin adnexal neoplasms_-part 1: an approach to tumors of the pilosebaceous unit. J Clin Pathol 2007;60:129-44.

33. Weiss SW, Goldblum JR. Benign tumors of peripheral nerves. In: Enzinger and Weiss's soft tissue tumors. Philadelphia, PA: Mosby, 2008:886-7.

34. Obaidat NA, Alsaad KO, Ghazarian D. Skin adnexal neoplasms - part 2: an approach to tumors of cutaneous sweat glands. J Clin Pathol 2007;60:145-59.

35. D'Amato MS, Patterson RH, Guccion JG, et al. Porocarcinoma of the heel. A case report with unusual histologic features. Cancer 1996;78:751-7.

36. White EA, Rabinovitz HS, Greene RS, et al. Pigmented basal cell carcinoma simulating melanoma in a burn scar. Cutis 2003;71:404-6.

37. Aguilar A, Schoendorff C, Lopez Redondo MJ, et al. Epidermotropic metastases from internal carcinomas. Am J Dermatopathol 1991;13:452-8.

38. Christine MA, Humphreys TR, Lee JB. Epidermotropically metastatic pancreatic adenocarcinoma. Am J Dermatopathol 2006;28:60-2.

39. Garcia-F-Villalta MJ, Adrados M, Dauden E, et al. Pigmented metastasis of breast carcinoma mimicking malignant melanoma. J Eur Acad Dermatol Venereol 2004; 18:223-4.

40. Luis R, Yus ES, Nunez C, et al. Epidermotropically metastatic breast carcinomas: rare histopathologic variants mimicking melanoma and Paget's disease. Am J Dermatopathol 1996;18:385-95. 